\title{
LAS SANCIONES PROCESALES Y DISCIPLINARIAS FRENTE A LA INFRACCIÓN A LAS NORMAS DE DISTRIBUCIÓN DE CAUSAS ENTRE TRIBUNALES CIVILES
}

\author{
PROCEDURAL AND DISCIPLINARY SANCTIONS FOR THE \\ INFRINGEMENT OF RULES OF TRIAL DISTRIBUTION AMONG CIVIL \\ COURTS
}

IgNACIO Ried UndurRagA ${ }^{1}$

\begin{abstract}
RESUMEN: La búsqueda de un tribunal ventajoso para los intereses de alguna de las partes en el proceso civil, ha llevado a ciertos litigantes a implementar mecanismos que permitan burlar el sistema aleatorio de distribución de causas en aquellos territorios que son asiento de Corte. En este trabajo se explica y fundamenta que la consecuencia procesal de esta infracción normativa es la incompetencia absoluta del tribunal civil respectivo. Asimismo, se expondrá acerca de las sanciones disciplinarias que nuestra jurisprudencia ha venido aplicando en forma consistente durante los últimos años para reprimir estas conductas.
\end{abstract}

Palabras clave: Distribución de causas, Incompetencia, Sanciones disciplinarias a abogados.

ABSTRACT: The pursuit of a convenient civil court, has led some parties on trial to create mechanisms to circumvent the random distribution system of trials among the inferior civil courts. This paper explains and substantiates the procedural consequence of this rule violation, as the absolute incompetence of the respective civil court. Also, it refers to the disciplinary sanctions that have consistently been applied in recent years to curb these behaviors.

Key words: Trial distribution system, Incompetence, Disciplinary sanctions on lawyers.

\section{LA AUTONOMÍA DE CADA JUZGADO EN LA INTERPRETACIÓN Y APLICACIÓN DE LA LEY PROCESAL Y EL SURGIMIENTO DE LOS USOS Y COSTUMBRES FORENSES, COMO CAUSAS DE LA PREFERENCIA DE UN JUZGADO POR SOBRE OTRO}

La autonomía del Poder Judicial no solo se predica respecto de los restantes poderes del Estado, sino también respecto del funcionamiento interno de cada tribunal en relación con sus pares y sus superiores. Es decir, la Constitución no solo proscribe la intromisión del Ejecutivo y del Congreso en las gestiones llevadas ante los tribunales; sino que además cada uno de los tribunales y Cortes del país, individualmente considerados, es independiente respecto de los restantes órganos que ejercen jurisdicción. Por otra parte, la dependencia funcionaria, económica y disciplinaria de los tribunales ordinarios respecto de la Corte Su-

\footnotetext{
${ }^{1}$ Abogado. Licenciado en Derecho de la Pontificia Universidad Católica de Chile. Máster en Derecho Penal y Ciencias Penales de la Universidad de Barcelona y Universidad Pompeu Fabra, Barcelona, España. Profesor del curso de Litigación y Estrategia Civil de la Facultad de Derecho de la Universidad Diego Portales. Dirección postal: Av. Andrés Bello 2711, piso 8, comuna de Las Condes, Santiago. Correo electrónico: iried@bmaj.cl.
} 
prema, en caso alguno significa que esta última pueda dar instrucciones o imponer en qué forma debe un tribunal inferior resolver un determinado caso legalmente sometido a su competencia (sin perjuicio de la existencia de un sistema de recursos procesales). Las Cortes superiores pueden influir en los inferiores mediante la auctoritas de sus sentencias sobre casos análogos resueltos en el pasado, no así mediante la potestas de su jerarquía para imponer su criterio a casos nuevos. Esta independencia es un rasgo esencial del Poder Judicial, y garantiza la imparcialidad del juzgador: la decisión del juez inferior que desagrada a la del superior no es motivo para remover al primero. La autonomía de cada tribunal individualmente considerado es una consecuencia de la forma en que está concebida la competencia en relación al principio de inavocabilidad del art. $8^{\circ}$ del Código Orgánico de Tribunales, que inhibe a cada juzgado de inmiscuirse en los asuntos que son competencia de otro tribunal ${ }^{2}$. Esta autonomía no sería un problema si cada juzgado hiciera una interpretación uniforme de la ley, en especial, en lo que me interesa en este trabajo, de la ley procesal. De todas formas, esa interpretación uniforme es una utopía, y es ciertamente desaconsejable. La utopía positivista de que el juez simplemente debe limitarse a aplicar la ley al caso concreto, constituye un deseo que desde el siglo XIX alberga el legislador. El juez es el destinatario de la norma procesal, que aplica al caso, y al aplicarla, crea asimismo una nueva "norma" (sentencia) ad hoc para el problema que se le ha presentado. Y como el legislador no pudo prever todos los casos que a un juez se le presentan, las normas procesales deben ser interpretadas y adecuadas a cada caso, generando una verdadera fuente del Derecho procesal, compuesta por los innumerables usos de cada juzgado, que muchas veces llenan vacíos legales y otras derechamente contravienen la propia ley ${ }^{3}$. Y en esta función de interpretación de la ley procesal el juez es completamente autónomo. Así, no es raro encontrar en un mismo territorio jurisdiccional, que existen jueces civiles restrictivos con la concesión de medidas prejudiciales, mientras otros son especialmente laxos; o jueces en extremo expeditos, frente a otros más lentos, etc. Es este tipo de situaciones -más allá de ciertos casos aislados de corrupción que pueden existir- lo que lleva a ciertos litigantes a preferir un tribunal civil por sobre otró ${ }^{4}$.

Nuestro ordenamiento jurídico, sin embargo, prohíbe expresamente que el interesado en iniciar un proceso escoja un tribunal según su preferencia. Para asegurar que ninguna persona ocurrirá al tribunal civil de su conveniencia, existe un sistema automático

\footnotetext{
2 Como acota Silva Bascuñán (1997) p. 530, se trataría de una manifestación de la "independencia personal de los magistrados", la que estaría "asegurada mediante un estatuto que rija los requisitos de incorporación, permanencia y término de sus funciones, en tales condiciones que les sea posible entregarse de lleno a sus tareas y adoptar sus decisiones sin riesgo alguno de verse perturbados en su persona misma”. NIEVA (2014) p. 85, señala que "los jueces no están sometidos al principio de jerarquía, lo que significa que no deben obedecer órdenes, ni siquiera meras instrucciones de los tribunales superiores. Por ello, los tribunales superiores, solo a través de los recursos contra las resoluciones judiciales, pueden corregir la interpretación del ordenamiento jurídico que hagan los inferiores. Y tampoco pueden darles instrucciones sobre la interpretación o aplicación del ordenamiento jurídico, ni en general ni mucho menos en un caso concreto".

3 Nieva (2014) p. 38: "Lo más destacable de la interpretación de las leyes procesales es que, en la enorme mayoría de los casos, existe una identidad entre el destinatario de la norma y su intérprete en la persona del juez", lo que provoca que el uso y costumbres forenses tengan la mayor importancia en el proceso.

4 Romero (2014) p. 50: “sin ánimo de agotar la casuística, por ejemplo, en aquellas comunas o agrupaciones de comunas en cuyo territorio existan dos o más jueces con igual competencia, es frecuente que se espere el turno del tribunal al que se estima más benigno con la tesis que se defenderá para presentar la demanda o gestión”.
} 
de distribución de causas, que mediante un algoritmo informático, distribuye las distintas demandas y gestiones entre los tribunales civiles de un mismo territorio jurisdiccional que sea asiento de Corte. Este algoritmo funciona sobre la base de cierta información que la parte debe indicar en una "pre-suma" obligatoria, donde debe consignar los nombres y números de Rol Único Tributario de todas las partes y de los apoderados de la solicitante. El sistema está diseñado para asignar a un mismo tribunal todas las gestiones solicitadas entre las mismas partes, de forma de evitar forzosamente el "vitrineo de tribunales" $y$ de radicar ante un mismo juez todos los conflictos que pudieran estar conectados, y así favorecer la acumulación de procesos, y evitar problemas de litis pendencia o de cosa juzgada. A pesar de la implementación de este sistema, la posibilidad de burlarlo existe y hasta algún tiempo se estimó que era una práctica generalizada entre ciertos abogados. La forma de vulnerar el sistema computacional de distribución de causas no exigía un mayor esfuerzo que simplemente presentar varias solicitudes idénticas en su contenido, en las que solamente se consignaban presumas diferentes, omitiendo o agregando algún nombre o número de Rol Único Tributario. De esta forma, el litigante se hacía de una serie de gestiones asignadas a diferentes tribunales, pudiendo luego elegir ante cuál de ellos continuar la tramitación, según le conviniera de acuerdo al "perfil" de cada juzgador.

Esta irregularidad constituyó un desafío importante para los distintos operadores jurídicos, sobre todo los tribunales civiles y las respectivas Cortes, para determinar y fundamentar cuál era la consecuencia procesal cuando se advertía que se había empleado esta maniobra. En este sentido, parece existir consenso en el foro y en el Poder Judicial acerca de que estas conductas deben ser reprimidas ${ }^{6}$. Existe jurisprudencia reciente y relativamente asentada, que estima -creemos, con razón- que las normas sobre distribución de causas son reglas de orden público, y por lo mismo, acarrean la incompetencia absoluta del tribunal que ha recibido la competencia en virtud de la alteración de los sistemas informáticos. Asimismo, existe jurisprudencia de nuestros tribunales superiores que han sancionado disciplinariamente a quienes han incurrido en estas prácticas, llegando también el Tribunal Constitucional a pronunciarse acerca de la legalidad de estas reglas sancionatorias. En este trabajo se tratará someramente acerca de las consecuencias procesales y disciplinarias que acarrea la infracción a las normas sobre distribución de causas. Hasta el momento, nuestra doctrina procesal ha abordado el problema solo desde la óptica de meros errores administrativos o involuntarios en la designación del tribunal mediante este sistema; en este trabajo se abarcan las consecuencias procesales de un verdadero fraude de ley como es la radicación irregular de un asunto ante un tribunal de conveniencia de la parte ${ }^{7}$.

\footnotetext{
5 Romero (2014) pp. 125-126, describe en más detalle este sistema.

6 Así, el Boletín No 9.679-07 en estudio por la Comisión de Constitución, Legislación, Justicia y Reglamento del Senado, propone "reemplazar el actual sistema de distribución de causas por turnos, estableciendo un sistema informático idóneo, que aplicaría el primer juzgado de letras de cada comuna o agrupación de comunas. La iniciativa se fundamenta en los efectos negativos del sistema de turno, que permite a las partes "elegir" el tribunal en el que presentarán su demanda, produciendo una distribución inequitativa de la carga de trabajo en tribunales equivalentes".

7 Como acotan López y Arnaiz (2008) p. 4: "un cierto fraude de ley a través del direccionismo en el planteamiento de escritos por los justiciables, eligiendo no ya el órgano competente sino al concreto titular de la potestad jurisdiccional, es decir, al juzgado o sección competente".
} 


\section{LAS REGLAS SOBRE DISTRIBUCIÓN DE CAUSAS COMO NORMAS DE COMPETENCIA ABSOLUTA}

Las reglas sobre distribución de causas entre tribunales civiles de igual jerarquía, dentro de un mismo territorio asiento de Corte, están contenidas en el artículo 176 del Código Orgánico de Tribunales, complementado por el Auto Acordado de la Corte de Apelaciones de Santiago sobre Minutas para Demandas Nuevas, de 19 de diciembre de 1988, publicado en el Diario Oficial de 21 de enero de 1989, y por el Auto Acordado de esa misma Corte, de 29 de octubre de 1993, publicado en el Diario Oficial de 3 de noviembre de ese año. El inciso primero de la primera de estas normas dispone que "en los lugares asiento de Corte en que hubiere más de un juez de letras en lo civil, deberá presentarse a la secretaría de la Corte toda demanda o gestión judicial que se iniciare y que deba conocer alguno de dichos jueces, a fin de que se designe el juez a quien corresponda su conocimiento". Esta norma dispone que es la Corte de Apelaciones respectiva, a través de su secretaría, la que debe designar el tribunal civil competente. Dados los enormes volúmenes de gestiones ingresadas a distribución a las Cortes, y para asegurar la imparcialidad del proceso, es que se dictaron los autos acordados antes referidos, que a través del sistema automático ya descrito, efectúa materialmente la designación del respectivo juzgado civil en forma aleatoria.

Esta norma recién transcrita no es, en absoluto, disponible para las partes. El litigante no puede elegir, de entre los tribunales civiles de un mismo territorio, ante quién presentar su demanda. Esta sola circunstancia -el carácter indisponible, irrenunciable y perentorio- nos debiera llevar a pensar que se trata de una norma de orden público, que al regular la competencia, establece una norma de competencia absoluta. Y por lo mismo, un tribunal que se avoque a conocer de un asunto en contravención a esta norma, será absolutamente incompetente. Pero más allá de la literalidad de esta norma orgánico-constitucional, su carácter de orden público se desprende de ser la concreción normativa del principio constitucionalmente garantizado del derecho al juez natural, como se dirá más adelante. Este principio, de orden público, no protege (solamente) un interés privado de la parte, sino eminentemente un interés público ${ }^{8}$.

Existe, sin embargo, una atávica confusión acerca del carácter de estas normas de distribución de causas. Por un lado, hay abundante jurisprudencia que ha estimado que estas normas son solo un asunto doméstico de carácter exclusivamente económico para lograr una distribución equitativa del trabajo en el conocimiento de asuntos entre tribunales de igual jerarquía dentro de un mismo territorio, descartando que se trate de normas de

\footnotetext{
8 Existe cierta confusión acerca del contenido de los derechos y sus fundamentaciones. La normas sobre distribución de causas son de orden público, sin perjuicio que una de sus fundamentaciones pueda mirar al interés privado de una de las partes en juicio. AleXY (2013) p. 181 ha dicho que "si se distingue entre fundamentaciones de los derechos y los derechos como posiciones y relaciones jurídicas, aparecen como fundamentaciones no solo bienes individuales tales como los intereses del respectivo titular del derecho o su libre albedrío, sino también bienes colectivos". AlESSANDri et al. (1998) p. 46 definen las normas de orden público las "que, para los supuestos que consideran, imponen necesariamente su propia regulación, sin permitir a los particulares prescindir de ella y establecer otra prescripción diversa”.
} 
competencia" ". Asimismo, está la opinión del profesor Nicolás Luco, quien estima que estas serían normas de competencia relativa, y por lo mismo disponibles para las partes. Es necesario analizar cada una de estas posiciones para desecharlas, y arribar a la doctrina correcta, que es que se trata de normas de orden público, de rango orgánico-constitucional, y por lo mismo, indisponibles para las partes.

La consideración de las normas sobre distribución de causas como un asunto meramente "doméstico", administrativo o económico puede tener su base en el análisis formal "en cascada" de las normas de competencia. Así, en cualquier manual de Derecho Procesal se dice que para saber qué tribunal debe conocer de un asunto, debe comenzarse por aplicar las normas de competencia absoluta: fuero, materia y cuantía. Y una vez despejados estos factores, se aplican las reglas sobre competencia relativa, esto es, el factor territorio y la eventual prórroga pactada por las partes. En este análisis en dos etapas, queda para el final, en tercer lugar, la determinación del tribunal preciso que deberá conocer de un asunto. Esta determinación se hace mediante las reglas de distribución o del turno. Y como ya se han aplicado las reglas sobre competencia absoluta y relativa, parece ser que "por descarte" (o sea, como "no puede ser" una regla de competencia absoluta ni relativa) se llega a esta solución de asignarles un carácter meramente económico o doméstico, carente de importancia, y por lo mismo, sin mayores consecuencias cuando se vulneran.

Por otra parte, el profesor Luco ha elaborado una tesis novedosa, en que rechaza que se trate de reglas meramente económicas, afirmando que son de competencia relativa, y por lo tanto, disponibles por las partes. Señala que no hay fundamento legal para sostener que se trata de normas de orden público, y que no existiría coherencia ni proporcionalidad en un sistema orgánico que por un lado permite - por ejemplo- a las partes prorrogar convencionalmente la competencia para ante los tribunales de la ciudad de Arica, en circunstancias que los que debían conocer naturalmente del asunto eran los de la ciudad de Punta Arenas, pero que establece la incompetencia absoluta del tribunal designado erróneamente por el sistema de distribución de causas ${ }^{10}$.

Luco refuta así la "doctrina tradicional" de los procesalistas Anabalón y Casarino, quienes han sostenido que las normas de distribución de causas son de orden público, pero a mi juicio yerra al decir que es lo mismo radicar un asunto en cualquiera de los juzgados civiles de Arica o de Punta Arenas, que radicar una gestión ante un juez específico de cualquiera de esas dos ciudades. En el primer caso, la ley permite que las partes prorroguen la competencia ante los juzgados civiles de un determinado territorio, sin elegir un juez en particular. O sea, se acota la nómina de posibles jueces, sin elegir a uno en específico. En el segundo caso, lo que estarían haciendo es designar a un juez ordinario ad hoc para que se

\footnotetext{
9 Romero (2014) pp. 127-128. El autor reproduce extractos de fallos en que se manifiesta esta tendencia jurisprudencial. En apoyo de esta tesis se pronunció el fallo del Tribunal Constitucional 22 de julio de 1993, comentado por TaVolari (1993). En el mismo sentido, Oberg y Manso (2011) p. 41, quienes señalan que "la jurisprudencia ha resuelto que el turno 'no constituye propiamente una regla de competencia (...) son solo una medida de orden y buen gobierno judicial'”.

10 LuCo (2002) p. 26.
} 
avoque a conocer de un determinado asunto ${ }^{11}$. Es precisamente esto último lo que la norma del artículo 176 del Código Orgánico de Tribunales pretende evitar: que se pueda elegir a un determinado funcionario del Poder Judicial, según la conveniencia de las partes. Este autor dice que "no hay ningún fundamento legal", pero lo cierto es que sí lo hay; y realmente lo que está comprometido aquí es la garantía constitucional del juez natural del art. 19 No 3 inciso $4^{\circ}$ de la Constitución Política de la República: "nadie puede ser juzgado por comisiones especiales, sino por el tribunal que le señalare la ley y que se hallare establecido con anterioridad a la perpetración del hecho", que es parte integral del derecho al debido proceso. En el caso chileno, la ley encomienda a la secretaría de la respectiva Corte de Apelaciones la designación del tribunal específico que conocerá del asunto, sin que las partes puedan intervenir en dicha designación. No existe otra forma de garantizar la independencia e imparcialidad del Poder Judicial que no sea el inhibir mediante una ley orgánica que las partes puedan elegir a sus jueces. En este mismo sentido, sería contrario a cualquier idea de justicia o probidad que un ciudadano pudiera elegir al policía, al fiscalizador de impuestos internos, al fiscal del Ministerio Público o al funcionario específico con quien "atenderse" en una repartición pública cualquiera ${ }^{12}$.

Un sistema en que las partes pudieran elegir el juez civil ordinario que resolviera sus asuntos presenta, evidentemente, serios reparos de todo tipo. No solo puede acarrear una desigual distribución del trabajo, como advierte Luco, sino generar perversos incentivos para los operadores jurídicos, y devenir en un escenario propicio para el tráfico de influencias y la corrupción. Además, sería un sistema ciertamente injusto. En aquellos casos en que las partes acuerden someter sus litigios ante un tribunal en particular, se generará una situación desigualmente arbitraria frente a aquellos ciudadanos que no hicieron esa

\footnotetext{
${ }^{11}$ En este sentido, dicen LópeZ y Arnaiz (2008) p. 7, que "si el legislador permite legalmente que en la configuración del juez competente las partes puedan disponer de la competencia territorial o circunscripción a la que se someten, no permite en cambio la elección del trabajo en la administración de justicia y, consiguientemente, su eficacia; ya sea por evitar los jueces ad hoc, ya sea por evitar, como dice el propio precepto, que "las partes puedan someterse a un determinado tribunal con exclusión de los otros" (se refiere al art. 57 de la Ley de Enjuiciamiento Criminal española). Quiebra en este punto esa máxima que establece que quien puede lo más puede lo menos. Y es que, pese a que se puede en determinados casos disponer de la competencia, en ninguno puede disponerse del reparto, y ello tal vez sea porque no nos encontramos ante una cuestión menor o sin trascendencia procesal, pese a que la naturaleza de estas normas sea de naturaleza gubernativa".

12 MuerZa (2001) p. 454: "estas normas tienen gran importancia, pues encuentran su fundamento constitucional en el derecho al juez ordinario predeterminado por la ley o juez legal previsto en el artículo 24.2 de la Constitución (de España)". En el mismo sentido, Colmenero (2007) p. 6: "las normas de competencia y procedimiento, además de servir de instrumento para actuar la potestad jurisdiccional y para hacer efectiva la tutela jurisdiccional de los ciudadanos, tienen que conseguir un reparto de trabajo, racional y razonable, en el ámbito de la Administración de Justicia, para un funcionamiento eficaz y eficiente que permita a la jurisdicción atender las funciones que tiene encomendadas. Pero los requerimientos constitucionales no terminan con la exigencia de unas normas de competencia y procedimiento, puesto que dichas reglas deben ser conjugadas con el derecho fundamental de los ciudadanos a un juez ordinario predeterminado por la ley (art. 24.1 CE), lo que en el ámbito en que nos situamos exige, entre otras cuestiones, que el conocimiento del pleito venga atribuido al Juez por normas con rango de ley anteriores a la incoación de las actuaciones de que se trate (art. 44 LEC). En el ámbito del Derecho Privado, la Ley Orgánica del Poder Judicial (en adelante, LOPJ) y la LEC establecen los criterios de reparto entre los diferentes órganos jurisdiccionales para hacer efectivo ese derecho al juez legal. Ahora bien, el ciudadano necesita saber, con precisión y exactitud, cómo se determina ese juez legal encargado de resolver su conflicto".
} 
designación en sus contratos, por ejemplo. Y en aquellos casos en que el demandante o solicitante altere el sistema automático de distribución de causas, la arbitrariedad es aún más evidente, ya que es el demandado quien se ve arrastrado al juzgado especialmente elegido por el demandante, a través de una verdadera trampa procesal.

Podría refutarse este argumento diciendo que de acuerdo al sistema chileno, las partes son soberanas en designar un juez árbitro ad hoc para que conozca de un determinado conflicto. Esta refutación no puede ser admitida, por cuanto no puede estimarse que la función pública del Poder Judicial, que tiene el imperativo legal de conocer y juzgar de toda clase de asuntos, es homologable a las funciones que ejercen los jueces árbitros en el marco de conflictos civiles y comerciales privados entre particulares. Así, resulta perfectamente aceptable que dos empresas sometan un incumplimiento contractual a un arbitraje privado; sin embargo, nos parecería aberrante que la Superintendencia de Valores y Seguros acuerde con un particular resolver sus diferencias ante un árbitro privado; o que un particular recurra a un árbitro para tramitar un cambio de nombre o una posesión efectiva. Existen así numerosas materias que son de competencia de los juzgados civiles, en que la elección de un tribunal específico - por existir intereses públicos comprometidos- resultará inconveniente.

Son estas mismas razones de probidad administrativa, transparencia institucional, justicia e imparcialidad, las que llevan a rechazar también los argumentos que nuestra doctrina y jurisprudencia ha sostenido, en el sentido que las reglas de distribución de causas serían meramente disposiciones de carácter económico o administrativo, cuya infracción no genera mayores consecuencias ${ }^{13}$.

Es, por lo tanto, la llamada "doctrina tradicional" la correcta; esto es, que las reglas sobre distribución de causas son de orden público, y su contravención acarrea la incompetencia absoluta del tribunal que erróneamente se avocó al conocimiento del asunto. Entre

13 Entre otras sentencias recientes de nuestros tribunales superiores, puede citarse la del caso BANCO EDWARDS CON MARCHANT (2010), en que la Corte de Apelaciones de Santiago señaló que "las reglas que determinan la distribución de causas entre jueces de igual competencia dentro de un determinado territorio, son de carácter económico y comoquiera que se aplican a tribunales igualmente competentes, no importan propiamente la incompetencia de uno u otro. Como dice la ley son reglas para la distribución de causas, no factores que determinen o asignen la competencia”. En el fallo del caso NUEVAMÉRICA CON ADMINISTRADORA (2010), señaló la Corte Suprema que "las reglas sobre distribución de causas, las que no alcanzan la entidad de reglas de la competencia, la inobservancia a su respecto no trae asignada, como sanción, la nulidad procesal, sino consecuencias de índole administrativa que no afectan el curso del litigio". Colombo (2004) p. 258 ha mantenido esta doctrina, señalando que "todos los tribunales existentes en una misma comuna son competentes y ello se debe a que la competencia se encuentra indicada solo por los cuatro elementos ya señalados: cuantía, materia, fuero y territorio, y estos determinan que tal tribunal o tal otro es el competente para conocer de un asunto. Que en el lugar que las reglas indiquen exista uno o más tribunales no altera en nada la competencia que la ley les señala, ya que han jugado todos los elementos de la competencia (...) estas reglas no son propiamente de competencia, sino solo "medidas tendientes a una repartición equitativa del trabajo", lo que implica que su omisión no involucre incompetencia del tribunal, sino solo sanciones de otra índole”. Este autor cita abundante jurisprudencia de comienzos del 1900 en el mismo sentido. 
nosotros, los procesalistas Mario Casarino ${ }^{14}$ y Carlos Anabalón ${ }^{15}$ adhieren a esta postura, y por su parte, Alejandro Romero, reconoce que se trata de normas no disponibles, si bien no es explícito respecto de la sanción procesal aplicable ${ }^{16}$. En el derecho argentino, encontramos al procesalista Podetti, quien también es de la misma idea ${ }^{17}$.

Existe jurisprudencia reciente que, en esta misma línea, ha reconocido correctamente que la contravención a las reglas sobre distribución de causas acarrea la incompetencia absoluta del tribunal ${ }^{18}$. Por lo tanto, la contravención a las reglas sobre distribución de causas no son simplemente infracciones a meras reglas económicas; por el contrario, se trata de la actitud muchas veces consciente de la o las partes de elegir un determinado tribunal de su conveniencia, lo que evidentemente abona el terreno para que surja la falta de imparcialidad del juzgador público que - por el motivo que sea- es "buscado" por las partes.

14 Casarino (2009) p. 149: "se trata de normas de orden público, pues han sido establecidas con el objeto de conseguir una mejor administración de justicia, mediante una justa y equitativa distribución del trabajo judicial entre los distintos tribunales de iguales jurisdicción y localidad. Así también han entendido este problema los jueces en la práctica, pues siempre que se les presentan demandas civiles que no les corresponde conocer, sea porque no están de turno, sea porque no ha habido distribución legal previa, se abstienen de tramitarlas, ordenando que se las interponga ante el tribunal que corresponda".

15 AnABALÓN (1970) p. 160: "no nos convence quienes sostienen que ellas constituyen una simple medida de orden y de buen gobierno judicial, tendiente a una mejor distribución del trabajo entre los juzgados (...) compelidos a encasillar el turno judicial y la distribución de causas, optamos por hacerlo, más bien, en la correspondiente a la competencia o incompetencia absolutas (...) no creemos que el legislador haya imaginado al fijar aquellas reglas, que pudieran ser objeto de prórroga de competencia, en cuyo caso se demostraría su inutilidad o ineficacia, sino que su propósito evidente fue el de establecer una limitación a la voluntad de las partes en esos casos".

16 Romero (2014) p. 128: "el hecho que estos preceptos se ocupen de un aspecto meramente administrativo no puede llevar a minimizar su rol en la determinación del juez natural. Es innegable que el legislador ha previsto estas normas para precisar al juez natural que debe conocer del asunto contencioso o voluntario, resultando imperativo que se respete tal designación".

17 Podetti (1954) p. 291.

18 En el caso Morales con COnstructora (2013), la Corte de Apelaciones de Santiago dijo que "cabe recordar que el Código Orgánico de Tribunales establece una serie de reglas o principios, denominados "reglas generales de competencia”, cuya finalidad es determinar la competencia de un tribunal para conocer de un asunto, por lo que dichas normas deben respetarse y no quedar sujetas al arbitrio de un litigante, en especial, las referidas normas tienen por finalidad evitar que un litigante pueda escoger el tribunal competente, así las cosas, al presentar dos demandas el actor claramente pretendió burlar el Sistema Informático creado para dar cumplimiento a la distribución de causas en los tribunales de la ciudad de Santiago”. A su turno, la Corte Suprema, rechazando una casación intentada respecto del mismo fallo dijo lo siguiente: "Que de conformidad con lo reseñado en el motivo que precede, se observa que los sentenciadores han hecho una correcta aplicación de la normativa atinente al caso de que se trata, toda vez que el actor interpuso una demanda el día 7 de noviembre de 2012, escrito que ingresó por medio del sistema de distribución de demandas de la Corte de Apelaciones de Santiago y que recayó ante el $10^{\circ}$ Juzgado Civil de Santiago; que posteriormente, el 8 de noviembre, distribuyó nuevamente la misma demanda, la que en este caso, recayó ante el 28 Juzgado Civil de Santiago. Al efecto, cabe recordar, que el Código Orgánico establece una serie de reglas o principios, denominados "reglas generales de competencia”, cuya finalidad es determinar la competencia de un tribunal para conocer de un asunto, por lo que dichas normas deben respetarse y no quedar sujetas al arbitrio de un litigante, en especial, las referidas normas tienen por finalidad evitar que un litigante puede escoger el tribunal competente, así las cosas, al presentar dos demandas el actor claramente pretendió burlar el Sistema Informático creado para dar cumplimiento a la distribución de causas en los tribunales de la ciudad de Santiago. En razón de lo anterior, siendo la primera de las demandas remitida al $10^{\circ}$ Juzgado Civil de Santiago, la competencia para conocer de la acción interpuesta quedó radicada en dicho tribunal, lo que impide al $28^{\circ}$ Juzgado Civil de esta ciudad conocer de la presente acción”. En el mismo sentido, el fallo del $28^{\circ}$ Juzgado Civil de Santiago del caso HipermerCAdos TotTUS CON INVERSIONES (2014). 
Esta tesis, sin embargo, no es pacífica, porque se estima que la contravención a una norma de orden público no debiera necesariamente acarrear la incompetencia absoluta del tribunal, sino que podría traer aparejada otra sanción, como sería la sola nulidad de los actos procesales. Sin embargo, y mientras siga vigente el Código de Procedimiento Civil, la nulidad de las actuaciones procesales es una sanción desaconsejable, ya que requiere la existencia de un perjuicio (procesal) para la parte que lo alega ${ }^{19}$. Tratándose de un tribunal que goza de plena competencia de acuerdo a las reglas de competencia absoluta y relativa, acreditar un perjuicio efectivo puede ser un gran escollo que deje impunes estas contravenciones. Sin perjuicio de las garantías fundamentales comprometidas -juez natural y debido proceso- es precisamente su poca concreción en el marco del proceso como fundamento de la nulidad procesal la que podría servir de resquicio para permitir que este tipo de maniobras no se sancionen. También debe mencionarse que algunas Cortes de Apelaciones resuelven de oficio ordenar una "corrección de carátula" cuando se detectan o son denunciadas situaciones en que un litigante ha presentado varias gestiones idénticas ante varios tribunales, burlando el sistema de distribución. En estos casos, parece ser que la Corte quita la competencia asumida irregularmente por el tribunal escogido por el litigante, y se reasigna el caso al tribunal a quien naturalmente debió corresponder el caso ${ }^{20}$. Sin perjuicio de lo anterior, parece obvio que la consecuencia natural, luego de declarada la incompetencia absoluta del tribunal designado irregularmente, será la declaración de oficio de la nulidad de todo lo obrado por ese tribunal.

19 La reforma del Código de Enjuiciamiento Criminal español del año 2000 vino a solucionar este tipo de problemas. Sin establecer explícitamente si las normas de "reparto" de asuntos entre los distintos tribunales de un mismo territorio jurisdiccional eran de competencia absoluta, relativa o meramente económicas, el artículo 68 estableció como sanción la nulidad frente a su infracción. En la exposición de motivos de esa ley, se señaló que se pretendía "una elemental disciplina en materia de reparto de asuntos que, como es lógico, atiende a sus aspectos procesales y a las garantías de las partes, procurando, al mismo tiempo, una mejor realidad e imagen de la Justicia civil. No se incurre, por tanto, ni en duplicidad normativa ni en extralimitación del específico ámbito legislativo. Una cosa es que la fijación y aplicación de las normas se entienda como función gubernativa, no jurisdiccional, y otra bien distinta, que el cumplimiento de esa función carezca de toda relevancia procesal o jurisdiccional”. NiEVA (2003) p. 153, estima que la infracción a las normas de reparto, al estar sancionada con nulidad según dispone el art. 469.3, corresponde a una causal de casación del fallo, ya que puede encuadrarse en los supuestos de la causal "infracción de las normas legales que rigen los actos y garantías del proceso".

20 Así sucedió en el caso C.M.N. (2014), en que la sala Tramitadora de la Corte de Apelaciones de Santiago, de oficio decidió lo siguiente: "Atendido el mérito de autos y los antecedentes tenidos a la vista, de los cuales se advierte que respecto de las causas que en su momento ingresaron a tramitación ante el Primer y Decimocuarto Juzgados Civiles de esta ciudad, una misma demandante realiza igual petición -cual es que se decrete una medida prejudicial precautoria en su favor- respecto de bienes de propiedad de idéntico demandado, anunciándose que interpondrá la acción que en definitiva concreta al presentar la demanda que se conoce ante el $26^{\circ} \mathrm{Juzgado}$ Civil de Santiago, y en consecuencia, por corresponder todos ellos a un mismo asunto, respecto del cual previno en su conocimiento el Primer Juzgado Civil al conceder la medida prejudicial solicitada, remítanse estos antecedentes y las causas Rol Ingreso de Tribunal No 9547-2014 y 20.970-2014, del Decimocuarto y Vigésimo Sexto Juzgados Civiles de Santiago, respectivamente, al $1^{\text {er }}$ Juzgado Civil de Santiago, por corresponder a este el conocimiento de los mismos. Ofíciese. Para tal efecto, corríjase computacionalmente las causas antes mencionadas. Asimismo, ofíciese al $14^{\circ}$ y $26^{\circ}$ Juzgados Civiles de esta ciudad, para informar lo resuelto". 


\section{LAS SANCIONES DISCIPLINARIAS EN LA JURISPRUDENCIA}

Un tema interesante, al que nuestra doctrina no ha destinado una sola línea, es el referido a las sanciones disciplinarias que de un tiempo a esta parte vienen imponiendo nuestros tribunales superiores a los abogados que deliberadamente han vulnerado las reglas sobre distribución de causas, alterando los sistemas informáticos. Es decir, y de acuerdo a la tesis que se intenta validar en este trabajo, la vulneración de estas reglas procesales no solo acarreará la incompetencia absoluta del tribunal, y la nulidad de lo obrado por el tribunal incompetente, sino que además podrá significar la imposición de una medida sancionatoria al abogado responsable. La existencia de esta jurisprudencia disciplinaria viene a refrendar la tesis sostenida en este trabajo en cuanto a la incompetencia del tribunal como sanción procesal, ya que sería incoherente que una determinada actuación procesal acarree graves sanciones al abogado, pero ninguna consecuencia en el proceso ${ }^{21}$. Al respecto, valga reproducir lo resuelto recientemente en dos fallos emanados del Pleno de la Corte de Apelaciones de Santiago, que luego fueron confirmados por el Pleno de la Corte Suprema. En el caso G.B.O. y H.B.F. (2009) 22 , dijo la Corte de Apelaciones de Santiago que: "si bien las partes son libres de hacer las solicitudes que estimen convenientes ante los tribunales de justicia, lo cierto es que estas han de estar dirigidas a un tribunal que por sorteo se le ha de asignar, no estando permitido escoger alguno de la conveniencia del solicitante y menos efectuar maniobras que disfrazan la realidad para así engañar el sistema de distribución computacional creado al efecto". Por su parte, en el caso J.P.G.M. (2014), la misma Corte resolvió "las dos solicitudes de medidas prejudicial precautorias son idénticas en cuanto al objeto pedido y causa de pedir, diferenciándose únicamente en la agregación en la segunda de ellas de una tercera empresa demandada, circunstancia que no tiene ninguna relevancia en cuanto al fundamento de su pretensión, de manera que ese dato parece haber sido incorporado por el solicitante para el solo efecto de alterar el sistema de distribución de demandas creado al efecto y escoger un tribunal de su conveniencia, como efectivamente ocurrió, al serle concedida la medida prejudicial precautoria en el segundo de los tribunales distribuidos (...) una vez identificado un negocio con determinados descriptores para posibilitar una equitativa distribución entre los treinta juzgados civiles que dependen de esta Corte, no es posible alterar esa identidad con miras a distraer el sistema de reparto que ha establecido este Tribunal, en búsqueda del mejor acatamiento del artículo 176 del Código Orgánico de Tribunales". En ambos casos, se confirmaron las sanciones aplicadas, de suspensión del ejercicio de la profesión durante un lapso de tiempo.

En estos casos, las Cortes superiores han aplicado la norma del artículo 543 del Código Orgánico de Tribunales, que sanciona las "faltas" cometidas por los abogados en

\footnotetext{
${ }^{21}$ López y Arnaiz (2008) p. 5: "no sería aceptable, en buena lógica y técnica jurídica, que una sanción gubernativa fuera la única consecuencia de la inaplicación o de la infracción de las normas no legales determinantes de que conozca un "juez ordinario", en vez de otro. Difícilmente podría justificarse la coexistencia de esa sanción gubernativa, que reconocería la infracción de lo que ha de predeterminar al "juez ordinario", y la ausencia de efectos procesales para quienes tienen derecho a que su caso sea resuelto por el tribunal que corresponda según normas predeterminadas".

${ }^{22}$ Los nombres de los abogados sancionados se han omitido.
} 
el ejercicio de sus funciones. Los abogados sancionados suelen reclamar respecto de este proceso, que se llevan adelante en expedientes reservados, y que no están sometidos a reglas formales en su tramitación; generalmente se solicita al abogado investigado que emita un informe dentro de cierto plazo, pero no se confiere la facultad de rendir prueba de ningún tipo, salvo aportar documentos. Asimismo, suele afirmarse que no existe un catálogo explícito de conductas prohibidas, ya que el referido artículo 543 solo habla de "faltas" sin concretar la conducta prohibida. De todas formas, la sentencia que aplica la sanción es recurrible de reposición ante el mismo Pleno de la Corte de Apelaciones que la pronunció, y de apelación para ante la Corte Suprema.

Un problema interesante, imposible de abarcar dada la extensión de este trabajo, es desde cuándo se hace efectiva la sanción aplicada: si desde desechada la reposición o solo cuando la apelación es rechazada poniendo fin al proceso. Esto, porque la ley no es explícita respecto del carácter devolutivo o suspensivo de esta apelación. A propósito de la sanción disciplinaria de suspensión del ejercicio de la profesión respecto del abogado defensor penal, que contempla el artículo 287 del Código Procesal Penal y del delito de desacato del artículo 240 del Código de Procedimiento Civil, se ha estimado con razón que la sanción solo opera una vez que se desecha el último de los recursos interpuestos, o sea, desde que queda firme, principalmente para permitir que el abogado sancionado se defienda ${ }^{23}$.

En el primer caso citado anteriormente (G.B.O. y H.B.F.), los abogados sancionados recurrieron de inaplicabilidad por inconstitucionalidad de esta norma, ante el Tribunal Constitucional, quien finalmente desechó el requerimiento, principalmente porque lo que se impugnó, más que la constitucionalidad de la norma, sería su aplicación concreta por el Pleno de la Corte de Apelaciones de Santiago. Sin perjuicio de ello, el Tribunal Constitucional hizo una interesante digresión acerca de la función disciplinaria, rechazando las alegaciones de los abogados recurrente, en el sentido que se habría vulnerado su garantía al debido proceso al imponerse una sanción a través de un proceso que no está regulado en la ley: "la facultad disciplinaria es esencial a la prestación de un buen servicio judicial $y$, en este sentido, la vinculación entre las facultades disciplinarias y las económicas resulta evidente. La facultad disciplinaria de la Corte Suprema, incluso para remover o trasladar a jueces, le ha sido atribuida por la Constitución, en su artículo 80, mientras la facultad disciplinaria de la Corte de Apelaciones se encuentra contemplada en los artículos 532 y siguientes, particularmente en el artículo 535 del Código Orgánico de Tribunales. Esta facultad disciplinaria, así consagrada en la Constitución y en la ley, está llamada a ejercerse. Tal ejercicio debe conformarse a la Constitución y a la ley. En aspectos en que el legislador no ha establecido normas o que expresamente la Constitución no le ha reservado a este, el propio órgano jurisdiccional puede autorregularse. Impedirlo haría imposible o enteramente discrecional el ejercicio de la facultad disciplinaria. Un Poder Judicial independiente y responsable de prestar un buen servicio a todas las personas, puede, a través de sus autoridades, regular el ejercicio de sus facultades disciplinarias por medio de autos acordados" 24 .

23 Cfr. Colegio de Abogados de Chile (2008) y Krause (2013) p. 1064.

24 Sentencia del Tribunal Constitucional de 16 de noviembre de 2010, rol 1568-2009-INA. 
Los pronunciamientos de nuestras Cortes superiores y del propio Tribunal Constitucional reafirman la importancia de las normas sobre distribución de causas como materializaciones de las garantías constitucionales de juez natural y debido proceso, y reconociendo tácitamente su carácter indisponible e irrenunciable para las partes.

\section{CONCLUSIONES}

1) Las normas sobre distribución de causas entre tribunales civiles con competencia en territorios que son asiento de Corte, tienen rango de ley orgánica constitucional (art. 176 del Código Orgánico de Tribunales) y están complementadas por dos autos acordados de la Corte de Apelaciones de Santiago.

2) Recogiendo la "doctrina tradicional", estas normas son de orden público, e indisponibles para las partes, por lo que su transgresión a través de mecanismos que alteren el sistema automático de distribución de causas acarrea la incompetencia absoluta del tribunal, y la nulidad de lo obrado por el tribunal irregularmente designado.

3) Esta postura desecha la teoría de que se trata de reglas simplemente económicas o administrativas, o incluso que son de competencia relativa, sobre la base de la manifiesta inconveniencia de que las partes en juicio (o una de ellas) escoja un tribunal de su conveniencia, comprometiendo así los principios de imparcialidad, transparencia y justicia que debe orientar la labor de los jueces, y constituye una vulneración del derecho fundamentalmente garantizado al juez natural.

4) Asimismo, existe reciente jurisprudencia de nuestras Cortes superiores y del Tribunal Constitucional que ha dictaminado sanciones disciplinarias a los abogados que han incurrido en prácticas tendientes a burlar los sistemas de distribución de causas, reafirmando el carácter de orden público, y la relevancia fundamental de estas normas como pilares del debido proceso.

\section{BIBLIOGRAFÍA CITADA}

Alessandri, Somarriva y Vodanovic (1998): Tratado de Derecho civil. Partes preliminar y general (Santiago, Editorial Jurídica de Chile).

AleXY, Robert (2013): El concepto y la validez del derecho (España, Editorial Gedisa).

Anabalón, Carlos (1970): Tratado práctico de derecho procesal civil chileno (Código Orgánico de Tribunales) (Santiago, Ediciones Seminario).

Casarino, Mario (2006): Manual de Derecho Procesal. Tomo I Derecho Procesal Civil (Santiago, Editorial Jurídica de Chile).

Colegio de Abogados de Chile (2008): "Acuerdo del Consejo General sobre Amparo Profesional presentado por don Matías Balmaceda Mahns".

Colmenero, José Antonio (2007): “Comentarios a la Ley de Enjuiciamiento Civil” (Barcelona). Disponible en: www.indret.com.

Colombo, Juan (2004): La competencia (Santiago, Editorial Jurídica de Chile).

Hart, Herbert L. A. (1998): El concepto del Derecho (Buenos Aires, Abeledo-Perrot) 
Krause, Soledad (2013): "Algunas consideraciones sobre el delito de desacato", en VAN WeEzel, Alex (edit.), Humanizar y renovar el Derecho penal. Estudios en memoria de Enrique Cury (Chile, Editorial LegalPublishing).

López, Raquel y Arnaiz, Amaya (2008): “Comentarios prácticos a la Ley de Enjuiciamiento Civil" (Barcelona). Disponible en: www.indret.com.

Luco, Nicolás (2002): "Naturaleza de las reglas del turno y distribución de causas y sanción a su infracción”, Revista de Derecho y Jurisprudencia, tomo XCIX, No 2: pp. 13-28.

Mañalich, Juan Pablo (2014): "Reglas primarias de obligación. Las "reglas del derecho penal en "El concepto del derecho", en Hart en la teoría del Derecho contemporánea. A 50 años de El concepto del Derecho (Ediciones Universidad Diego Portales).

Muerza, Julio (2001): "Del reparto de asuntos", en Cordón Moreno, Faustino (coord.), Comentarios a la Ley de Enjuiciamiento Civil, Vol. I (Navarra, Editorial Elcano Aranzadi).

NiEVA, Jordi (2003): El recurso de casación civil (Barcelona, Ariel Derecho).

Nieva, Jordi (2014): Derecho Procesal I. Introducción (Barcelona, Editorial Marcial Pons).

Oberg, Héctor y Manso, Macarena (2011): Derecho Procesal Orgánico (Santiago, Editorial AbeledoPerrot, tercera edición).

PodetTi, José Ramiro (1954): Tratado de la competencia (Buenos Aires, Editorial Ediar).

Romero, Alejandro (2014): Curso de Derecho procesal civil. Tomo II Los presupuestos procesales relativos al órgano jurisdiccional y a las partes (Santiago, Editorial LegalPublishing).

Silva Bascuñán, Alejandro (1997): Tratado de Derecho constitucional. Tomo I Principios Estado y Gobierno (Santiago, Editorial Jurídica de Chile).

Tavolari, Raúl (1993): "Comentario al fallo del Tribunal Constitucional de 22 de julio de 1993”, en Revista de Derecho y Jurisprudencia, tomo XC, 2a parte, sección 6a.

\section{JURISPRUDENCIA CITADA}

BANCO EDWARDS CON MARCHANT (2010): Corte de Apelaciones de Santiago, rol 4691-2006, de 5 de julio de 2010 (apelación y casación en la forma).

G.B.O. Y H.B.F. (2010): Pleno de la Corte de Apelaciones de Santiago, rol 2064-2009, de 20 de noviembre de 2009 (sanción disciplinaria a abogados).

NuEVAMÉRICA CON ADMINISTRADORA (2010): Corte Suprema, rol 4837-2009, de 5 de agosto de 2010 (casación en el fondo).

Sentencia del Tribunal Constitucional de 16 de noviembre de 2010, rol 1568-2009-INA.

Morales con Constructora (2013): Corte de Apelaciones de Santiago, rol 9609-2012, de

2 de agosto de 2013 (apelación); y Corte Suprema, rol 6887-2013, de 15 de octubre de 2013 (casación en la forma y en el fondo).

C.M.N. (2014): corte de Apelaciones de Santiago, rol 5772-2014, de 26 de enero de 2015 (corrección de carátula).

Hipermercados TotTus CON INVERSIONES (2014): $28^{\circ}$ Juzgado Civil de Santiago, rol C-1335-2014, de 9 de abril de 2014 (medida prejudicial precautoria).

J.P.G.M. (2014): Pleno de la Corte de Apelaciones de Santiago, rol 406-2014, de 28 de mayo de 2014 (sanción disciplinaria a abogado). 
Ried UndurRaga, Ignacio "Las sanciones procesales y disciplinarias frente a la infracción a las normas..."

\section{NORMAS CITADAS}

Constitución Política de la República

Código Orgánico de Tribunales

Código de Procedimiento Civil

Código Procesal Penal

Auto Acordado de la Corte de Apelaciones de Santiago sobre Minutas para Demandas Nuevas (19/12/1988), publicado en el Diario Oficial de 21 de enero de 1989.

Auto Acordado de la Corte de Apelaciones de Santiago, de 29 de octubre de 1993, publicado en el Diario Oficial de 3 de noviembre de 1993.

Ley de Enjuiciamiento Civil de España. 